Bennett Shapiro

\title{
Bioenergetic Boundary-Building
}


Bibliographic information of Die Deutsche Nationalbibliothek (The German Library) The Deutsche Nationalbibliothek lists this publication in the Deutsche Nationalbibliografie; detailed bibliographic data are available at http://dnb.d-nb.de.

2006 Psychosozial-Verlag GmbH \& Co. KG, Gießen, Germany

info@psychosozial-verlag.de

www.psychosozial-verlag.de

\section{(c) $\underset{\mathrm{BY}}{\mathrm{N}} \Theta$}

This work is licensed under the Creative Commons Attribution-NonCommercialNoDerivatives 4.0 International License (CC BY-NC-ND 4.0). This license allows private use and unmodified distribution, but prohibits editing and commercial use (further information can be found at: https://creativecommons.org/licenses/by-nc-nd/4.0/). The terms of the Creative Commons licence only apply to the original material. The reuse of material from other sources (marked with a reference) such as charts, illustrations, photos and text extracts may require further permission for use from the respective copyrights holder.

Cover image: Ferdinand Hodler Ausschreitende Frau ,1910, oil on canvas, 48,5 x $39 \mathrm{~cm}$

https://doi.org/10.30820/0743-4804-2006-16

ISBN (PDF-E-Book) 978-3-8379-6879-8

ISBN (Print) 978-3-89806-517-7

ISSN (Online) 2747-8882 · ISSN (Print) 0743-4804 


\title{
Bioenergetic Boundary-Building
}

\author{
Bennett Shapiro
}

\section{Summary}

The purpose of this article is to stimulate you to think about your own boundary issues and explore five components for strengthening your boundaries while experiencing three exercises. There are six sections:

I. Strong Boundaries vs. Weak Boundaries discusses how strong healthy boundaries are formed when, as infants/ young children, our outgoing impulses are met appropriately; conversely, weak boundaries result from our impulses being met inappropriately, and/or even hurtfully.

II. Which Boundary is More Like Your Own Boundary? asks you to consider if your boundary issues are »too loose«, »too tight «, or a combination of »loose « and »tight «.

III. Five Components of Bioenergetic Boundary-Building describes the energetic, muscular and psychological aspects of five major components for Boundary-Building, and each component's usefulness in tightening boundaries that are »too loose or loosening boundaries that are »too tight «.

IV. Three Physical Exercises for Strengthening your Boundaries gives you some direct experience of the five components; doing these exercises will help strengthen your boundaries and diagnose your boundary issues.

V. Utilizing Boundary Supports describes the various boundary supports, the effects of exercises involving these supports, theoretical explanations and implications for ongoing therapy.

VI. Future Investigations.

\section{Strong Boundaries vs. Weak Boundaries}

This article builds on my three recent longer papers on Bioenergetic Boundary-Building. In my explorations I have found the writings of Alexander Lowen to be very useful. 


\section{Strong, Healthy Boundary Formation}

A healthy boundary begins to be formed when, as an infant, we reach out to a parent with excitement, and our parent takes our baby hand gently, with a smile, and expresses an appropriate amount of either stimulating excitement or soothing calm. The boundary is the charged interface between our baby impulses and our parent's appropriate response to our impulses. Strong and healthy boundaries are formed when we reach out for satisfaction and fulfillment, and our natural instincts, impulses and feelings are met appropriately.

\section{A Boundary-Building Exercise}

To feel how a boundary is formed, bring the palms of both your hands together with even pressure. The stronger you press both hands together, the more charged will be their connection, and therefore the more charged and stronger the boundary will be.

Once a healthy boundary has been formed, it permits a constant stream of impulses from the core. Moreover, if the boundary formed in infancy / childhood is strong, it will usually remain strong for the rest of the person's life. As Dr. Alexander Lowen says (Lowen 1967, Chapter 3):

»The constant stream of impulses ... charges the periphery of the body so it is in a state of emotional readiness to respond ... a charged periphery is manifested in the tone and color of the skin, in the brightness of the eyes, in the spontaneity of gesture and in the relaxed state of the body musculature."

\section{Our Weak Boundaries}

Unfortunately, most of us had parents who did not respond appropriately often enough to our impulses and/or were overtly hurtful in their response. Then we contracted in fear and withdrew our natural impulses to avoid further painful contact. So our impulses became less frequent, more tentative, weak and sporadic; thus the periphery of our body never became fully charged. Consequently, almost all of us have weak boundaries. (The developmental trauma that caused our primal injuries also led to weak boundary formation; furthermore, character defenses can be seen as compensations for weak boundaries.) 
Bioenergetic Boundary-Building

Our weak boundaries are either undercharged, and/or lack the ability to respond emotionally and appropriately to events internal or external, as follows:

> Some of us have weak boundaries because they are too flexible, too porous, too permeable (»thin-skinned «) - so that we're easily overwhelmed by our own feelings or the feelings of others. Those of us with "flaccid schizoid «, »oral« or »borderline« issues have this problem; we lack access to assertive (aggressive) impulses (see person A, below.)

> Some of us have weak boundaries because they are too inflexible, too rigid, too impermeable (»thick-skinned «) - so that we have difficulty knowing our own feelings or being able to be touched by the feelings of others. Although it may seem that a rigid boundary would be strong, it is really weak in that it cannot respond emotionally to reality or to change reality in line with one's feelings. As Dr. Alexander Lowen wrote (Lowen 1983, Chapter 8), a rigid boundary is like a $»$ rigid rider on a horse, vulnerable to being thrown by any strong upsurge of movement or feeling «. Those of us with chiefly »narcissistic « issues have this problem; we lack access to tender heartfelt impulses. (See Person B, below.)

> Some of us have weak boundaries that are too porous, but, to be effective in the world, we compensate with a superficial rigidity in order to hold ourselves together. Those of us who are impulsive, reactive, hyperactive, or combine »borderline« and »narcissistic « issues, have this problem (see Person C, below.)

\section{Which Boundary is More Like Your Own Boundary?}

\section{Are You More Like Person A or Like Person B?}

Our boundaries regulate incoming stimuli and outgoing instincts, impulses and feelings. They do this muscularly, energetically and psychologically.

In the following diagrams, Person $A$ (Figure 1) has a boundary that is too permeable, too porous, whereas Person $B$ (Figure 2) has a boundary that is too impermeable, too rigid. 


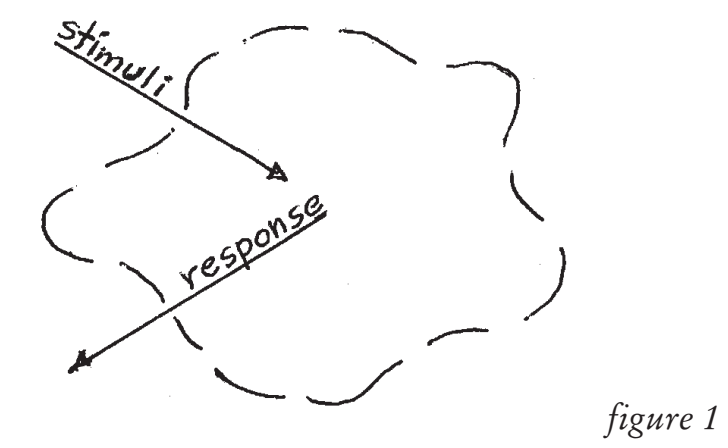

Person A

\section{Boundary Too POROUS}

If your boundary is too permeable, you often cannot prevent being overinfluenced by outside events (stimuli), nor can you always appropriately contain your reactions. In short, stimuli too easily get in and responses too easily get out.

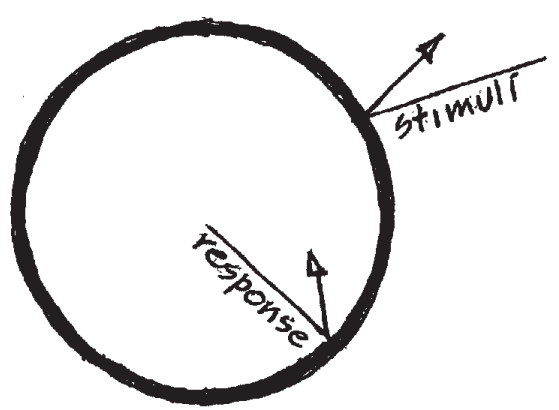

figure 2

\section{Person B}

Boundary Too RIGID

If your boundary is too impermeable, others often say they cannot reach you (they feel you won't let them in); moreover, you yourself feel you often cannot express your emotions fully. In short, stimuli can't easily get in, and responses can't easily get out. 


\section{... Or Are You More Like Person C?}

Person $C$ has a third type of boundary issue - a boundary that is a mixture of »loose« and »tight «.

Person C might seem to be more healthy, since the aspects of »loose « and »tight « might possibly complement each other and allow you to be more open or closed, as appropriate.

In fact, this possibility is an illusion. If you are Person $C$ you can easily end up closing off when being open is more appropriate, and vice versa. Or, if you are Person $\mathrm{C}$ you can be tooting along in your false self, thinking you are being appropriate, and out of nowhere get side-swiped by either the »loose « or the »tight « aspect.

Another illusion about Person $\mathrm{C}$ is that you could think that the »loose and »tight « aspects can neutralize each other's excessiveness; as though being nearsighted in one eye and farsighted in the other would somehow yield 20:20 vision.

\section{The Challenge}

The challenge for you is to be able to create a more healthy, stronger boundary that is neither Person A (»too loose«) nor Person B (»too tight «) nor Person $\mathrm{C}$ (a mixture of »loose« and »tight «).

Instead, your desired goal is a boundary that is more vulnerable and openhearted, and yet quite capable of protecting you.

However, strengthening your boundary state so that it becomes more healthy cannot be done only by trying to change. It comes mostly through working energetically with your body - because your boundary issues are largely dictated by muscular and energetic issues that are beyond your conscious control.

$>$ If our boundaries are »too loose« we need to strengthen them by accessing more fully our assertive (aggressive) impulses. This will strengthen our sense of ourselves; only then can we move more directly out into the world to claim and protect what is rightfully ours

$>$ If our boundaries are » too tight « we need to access more fully our vulnerable, sensitive and tender impulses. We can accomplish this by surrendering some of our character defenses; only then can we move more wholeheartedly out to others. 


\section{Five Components of Bioenergetic Boundary- Building}

Bioenergetic Boundary-Building consists of experiencing and applying five Components. In this section each of the five Components is briefly described and noted as to its usefulness in boundaries that are »too loose « or »too tight «. Note: An exercise position illustrates each component.

\section{Charging/Containing}

Charging/Containing involves tightening certain muscles to increase assertion (aggression), then gradually building a strong energetic charge, while containing it by preventing significant body movement and discharge.

Charging/Containing mobilizes and strengthens our assertive (aggressive) impulses, so we can then move more strongly, freely and fully into the world, and also permit us to claim what is rightfully ours.

If our boundaries are »too loose «, we lack access to our assertive/ aggressive impulses, which stem from deep within our core (not to be confused with reactive impulses that stem from being over-stressed). We also lack the ability to contain energetic charge. Since it focuses on charging, and containing that charge, Charging/Containing will thus be the most important component in which to gain proficiency.

If our boundaries are »too tight «, Charging/Containing our Resistance

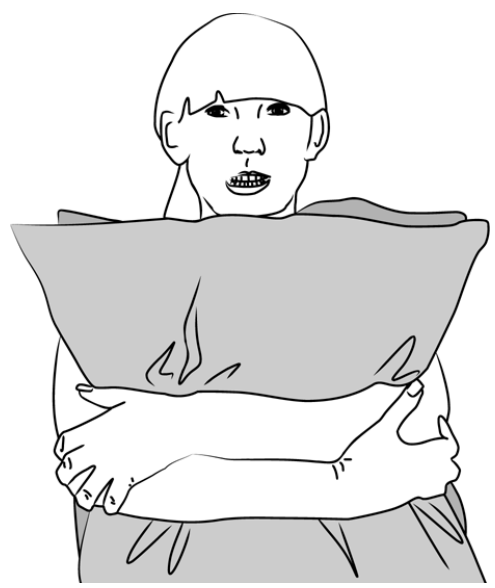
gives us a strong enough sense of self to take the risk of Surrendering our False Self and other character defenses. Surrendering will thus be the most important component in which to gain proficiency, but Charging/Containing, which is a necessity before the Surrendering, is highly important also.

Figure 3 illustrates a way to increase charge in the arms and hands - see Exercise 2, Step 5.

figure 3 


\section{Energizing Resistance}

Bioenergetic Boundary-Building involves muscular, energetic and psychological changes. Accordingly, we will resist these changes muscularly, energetically and psychologically. Energizing resistance lifts the barrier to exploring other components, especially Surrendering. Moreover, Charging/ Containing our resistance is itself a boundary-building tool.

If our boundaries are »too loose«, we probably have a flaccid, or a borderline, issue.

$>$ If our issue is flaccidity, our resistance will be unconscious and mainly muscular and energetic; we will use the defense of »collapsing « to express our resistance.

$>$ If we have a »borderline« issue, we will express our resistance by generating chaos and self-sabotaging (both externally and internally).

In both the above issues, the defense is not to become charged and/or not to contain that charge. Therefore, Charging/Containing exercises will be difficult but absolutely necessary.

If our boundaries are »too tight «, our resistance consists of a glorification of our image (false self) and also a denial of aspects of our personality that conflict with our image. However, this can be brought to consciousness and our protective aspect energized.

Figure 4 illustrates a way to energize Resistance. (This position is not used in any exercise in this article.)

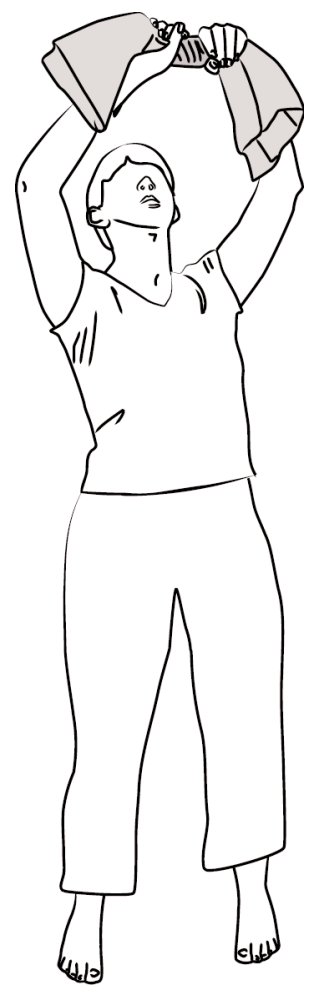




\section{Surrendering}

Most of us struggle in our life. The struggle can be between our ego states (e.g., »beating up on ourselves «) and/or we can project the internal struggle into the outer world - where we can struggle against someone or something. If we are struggling, we live in fear of experiencing a buried feeling. In fear, we pull $u p$ and $i n$ - thus becoming »up-tight «. If this fear is an old one from childhood, our fear of re-experiencing the fear is far more harmful for us in the present than it would be to re-experience the old characterological fear.

If our boundaries are »too loose«, we will confuse Surrendering (an egocontrolled »letting-go-to «) with »collapsing «, which is a defense. Only by Charging/Containing immediately before, can Surrendering have the probability of being genuine.

If our boundaries are »too tight «, Surrendering is the most important component to integrate.

Figure 5 illustrates a way to energize Surrendering. (This position is not used in any exercise in this article.)

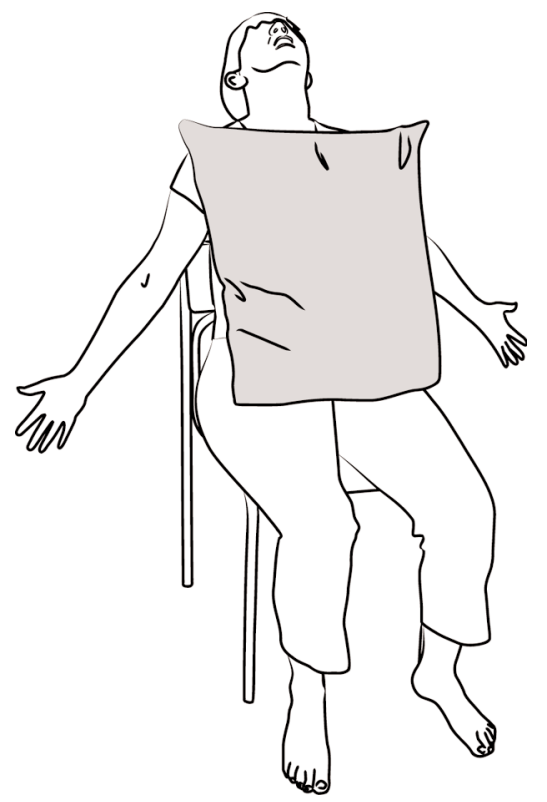

figure 5 


\section{Strengthening Adult Functioning}

Besides the muscular and energetic aspects of Boundary-Building, there is a psychological aspect, represented by the concept of a stronger 'Adult' functioning. Strong boundaries are a necessity for having strong Adult functioning; conversely, if our boundaries are weak, our Adult functioning will be weak. It's that simple.

If our boundaries are »too loose «, we are too easily overwhelmed by others, and conversely, too easily overwhelm others ourselves. Obviously, this implies a weak Adult functioning.

If our boundaries are »too tight «, we cannot easily let in the emotions of others, nor can we express ourselves openly to others; hence we can be seen and felt as rejecting. Again, our Adult functioning is weak, even though - or because it is rigid.

The three exercises in this paper focus on Strengthening Adult Functioning through the Adult communicating with the Natural Child. This whole area of communication between Adult / Ego and Natural Child / Body, as experienced in Exercises 1 and 3, is very exciting and has many implications yet to be explored.

Figure 6 illustrates a way to strengthen Adult functioning - see Exercise 2, Step 3.

figure 6

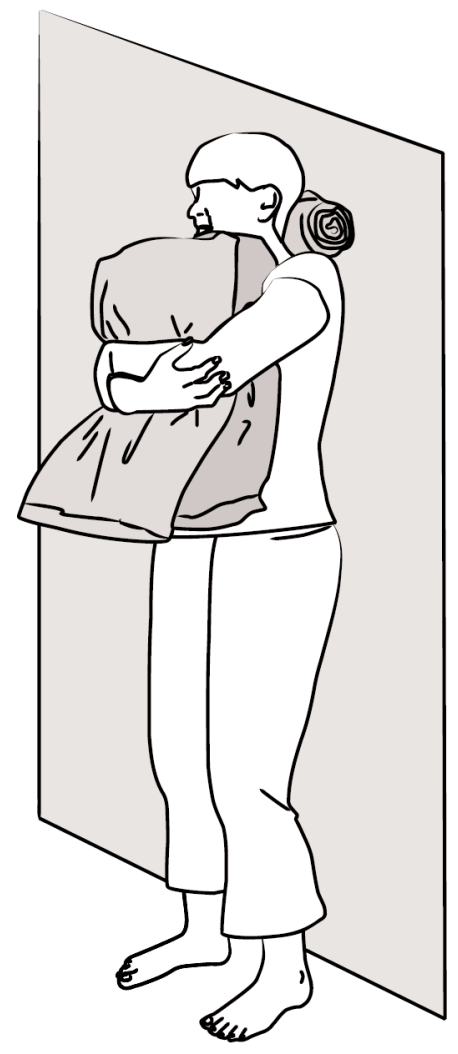




\section{Incorporating Boundary Supports}

The basic Boundary Supports include two sofa cushions stood up (vertical, on edge) and face-to-face, and three pillows. These can be utilized in several positions.

With the addition of Boundary Supports, most Bioenergetic exercises (even the simplest ones for beginners) are considerably more effective in bringing up the energetic charges more quickly, increasing the amount of energetic charge, and allowing the emotional affect to go deeper.

If our boundaries are »too loose «, the Boundary Supports will be comforting - giving us feelings of containment, assurance, security and safety. They provide the missing appropriate containing function, allowing us to risk more energetic charge.

If our boundaries are » too tight «, the softness and accepting nature of the Boundary Supports allow a relaxation and melting of the rigid characterological defenses that arose from rejection in childhood.

See Section $V$ for detailed comments about Boundary Support concepts and their implications for therapy.

Figure 7 illustrates a way to incorporate Boundary Supports. (This position is not used in any exercise in this article.)

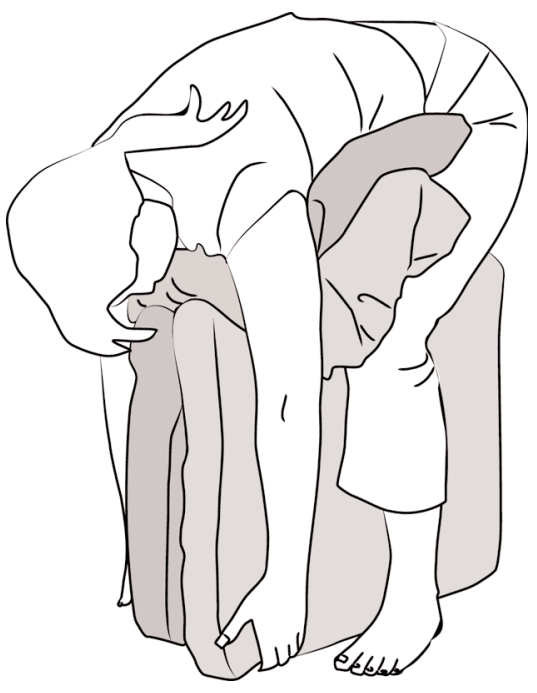

figure 7 
Bioenergetic Boundary-Building

\section{Governing Principles}

Depending on your boundary issue, the following principles govern how you apply the above five Components and the sequence in which you do certain exercises:

$>$ If your boundaries are »too loose « you will need to Charge/Contain;

$>$ If your boundaries are »too tight « you will need to Surrender;

$>$ If your boundaries are a combination of »loose « and »tight «, in certain circumstances you will need to Charge/Contain, in other circumstances you will need to Surrender;

$>$ Any Surrendering exercise must be immediately preceded by Charging/Containing your Resistance to the exercise; this acknowledges and honors the Resistance; also the Charging/Containing helps build a strong enough sense of self to permit the risk of Surrendering.

\section{Three Exercises for Strengthening your Boundaries}

Many exercises have been created for Bioenergetic Boundary-Building. They cover a wide range of characterological issues - the conflictual issues between our internal ego states; issues in our relationships with others; issues involved in our muscular and energetic holdings; and issues in our sexuality.

The exercises can be utilized in combination with each other to achieve different goals - e.g., a three-hour evening workshop for trainee recruitment; part of a program for boundary self-assessment (as the exercises can be quite diagnostic of whether your boundaries are »too loose « or »too tight «); a specific series of exercises for a particular client to use at home in a self-help program to build boundaries; several exercises done in a sequence that focuses on becoming more competent in one of the five Components, etc.

The following exercises focus on Strengthening Adult Functioning (component 4 , above).

Unfortunately, in most of us, our Adult is weak and/or not sufficiently present most of the time to fulfill his/her responsibilities as "president « of the »company « of ego states. And so our False Self acts »as if « it were the president, but it unfortunately is frequently overwhelmed by our introjected parental demonic (e.g., »beating up on ourselves «) or overwhelmed by the subsequent revenge of our child's devil (e.g., sabotaging our Parent's need for achievement in the world).

Since all three exercises require our Adult to communicate with our Nat- 
ural Child, our Adult has to come out of hiding and be more present, at least temporarily. Our Adult can then begin to acknowledge and integrate the Natural Child's energetic power, openness, heartfelt assertiveness, expressiveness, capacity for pleasure, etc. In turn, this strengthens Adult Functioning. (A basic Bioenergetic principle is that our Adult / Ego can only be as strong as its connection with our Natural Child / Body.) Our strengthened Adult can then have the courage to begin to address the needs both of our Primally Wounded Child and of our overworked Parent. (The Parent had to take responsibility for the survival of our »company « in the absence of the Adult.)

These exercises give you a sample of the wide range of muscular, energetic and psychological concepts needed for effective and efficient Bioenergetic Boundary-Building. Note that there is little mention of possible physical/ emotional effects, so as not to influence your own experiences.

Finally, it is the author's belief that, to strengthen boundaries, an ongoing exercise program at home (and even the workplace) is needed in addition to regular therapy sessions. Overcoming our resistance to doing exercises at home also contributes to strengthened Adult functioning - which strengthens our boundaries. Accordingly, the following exercises form the basis for a self-belp program.

\section{Exercise 1: Your Adult Communicating with Your Natural Child}

Exercise 1 serves as a fun and playful introduction to bow the Adult can communicate, using its language (words), with the Child, who then can respond with its own language (excitation and involuntary movement).

To communicate with the Natural Child, the Adult has to temporarily surrender some intervening protective layers - the False Self; next, the layer of deep distrust of the outside world (including the therapy and therapist); and, going further inward, the layer of the Primally Wounded Child. Any of these defensive layers can interfere with the attempt of the Adult to talk with the Natural Child directly and vice versa. For example, if you are overly concerned about your image (False Self), you wouldn't want to be heard talking to yourself, as in this exercise. 
Equipment: a standard armless chair.

1. Thoroughly ground yourself so that your legs are vibrating.

2. Sit toward the forward edge of the chair, as in Figure 8, and lean slightly forward so the weight is on the balls of your feet, and the top of your head lines up with your knees and the front of your toes.

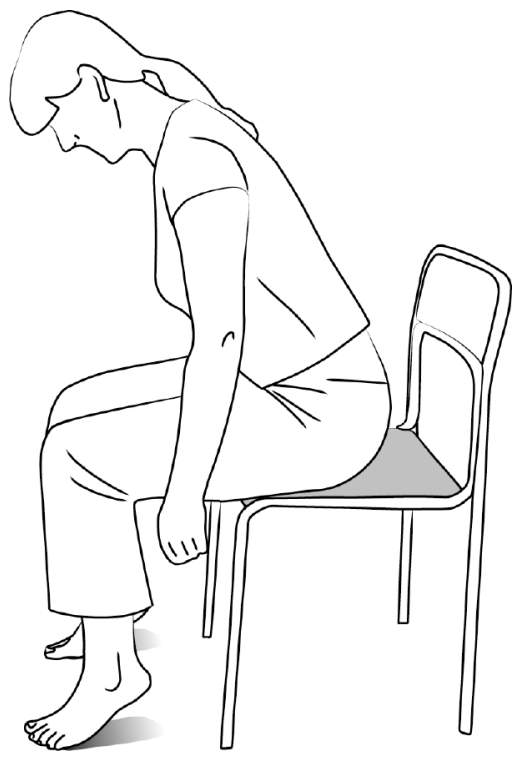

figure 8

3. Lift your heels slightly off the floor, as in Figure 9, but press them towards the floor. Hopefully your legs will begin to vibrate involuntarily in this position. (You must, however, remember to keep your heels off the floor.)

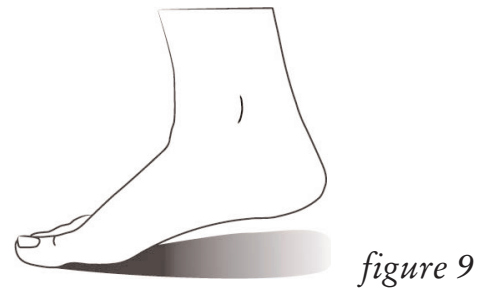

4. If your legs have difficulty vibrating, pump your heels up and down, pushing from the balls of your feet, and let some sound emerge. 
5. Once your legs are vibrating, talk to them out loud as if you were talking to two puppies who are excited about the possibility of going outside and playing. Say, »Would you like to go out and play? « Now briefly pause, and see and feel if your legs (puppies) respond by vibrating more strongly. Of course, the puppies are just a fun and easy representation of your Natural Child.

6. If you are excited by the increase of the involuntary excitation in your legs (puppies), open your eyes wider, purse your lips and make a drawnout, high-pitched, excited $\gg$ Ooooo! « sound.

7. Note if your legs (puppies) become more excited because you are appreciating their liveliness.

8. Continue talking out loud to your puppies (legs) and remember to show your appreciation by responding not only with words but also with excited eyes and sounds. Allow enough response time from your legs before making each new statement. Note their response to short and simple statements like the following: »You are so alive! « - »You are so exciting! « - I really like you! - Do you like me?«

9. Now try stroking your puppies (legs) while continuing to talk out loud to them - e.g.: »Do you like me stroking you? « Experiment with different types of touches accompanied by short questions or statements. Massage one leg while you talk to it. See if it becomes more alive than the other leg.

10. After you've had enough, stand up, bend over and let your legs continue to vibrate. If you feel like laughing at this whole experience, let it happen.

11. Now stand up and let yourself integrate the experience.

12. Close your eyes and check into your body. Do you feel more let down? more excited? some relief? some incredulity? Do you feel more lively? More positive about connecting with your Natural Child?

\section{Exercise 2: Your Adult Protecting Your Natural Child}

Charging/Containing is the cornerstone for quickly building a tangibly stronger sense of the peripheral boundaries of our body, a much stronger sense of our self, and more access to our assertive (aggressive) impulses. All of these are necessary for us to be able to move out into the world and claim what is rightfully ours. If our boundaries are "too loose", Charging/Containing is the most important Component for us, and it needs to be experienced daily at bome and/or work, especially when we feel the need to strengthen our sense of ourselves - like before going to see the boss and asking for a raise! 
In this exercise you will Charge/Contain your Adult so that it feels strong enough to protect your Natural Child. The exercise initially requires the support of a Bioenergetic colleague (therapist) as there are many opportunities for self-sabotage, particularly if you have a boundary that is »too loose«.

Read the following instructions before beginning, including the boxed section »Charging/Containing Errors - Watch Out! « that follows the exercise.

Equipment required: two or more pillows; a wall or door if available.

At some time previous you should have completed Exercise 1.

Most of us would have liked a Significant Other, like a good Aunt or Uncle, to have intervened to protect us, if they had been able to see our Parents or others injuring us developmentally. Imagine that the Significant Other (good Aunt or Uncle) is protecting your Child against a hurtful Parent by saying, »Stop it! I will not permit you to burt that Child any more!"

1. Ground thoroughly into your feet and legs so your legs are vibrating. Occasionally check to see that your feet remain planted on the floor, and your legs are vibrating.

2. Stand with your knees slightly bent, feet shoulder-width apart and your back against a wall, if available.

3. Hold two (or three) pillows to your chest by crossing your arms in front of the pillows and holding on to your elbows. See Figure 10. (Some people use this position when they are cold or distraught and/or »holding themselves together «.)

4. Squeeze the pillows into your chest and drop your shoulders as much as possible.

5. Experiment with increasing the charge in your arms and hands by trying to pull your elbows together and, at the same time, squeezing the pillows more firmly into your chest, as in Figure 11. Now relax your arms.

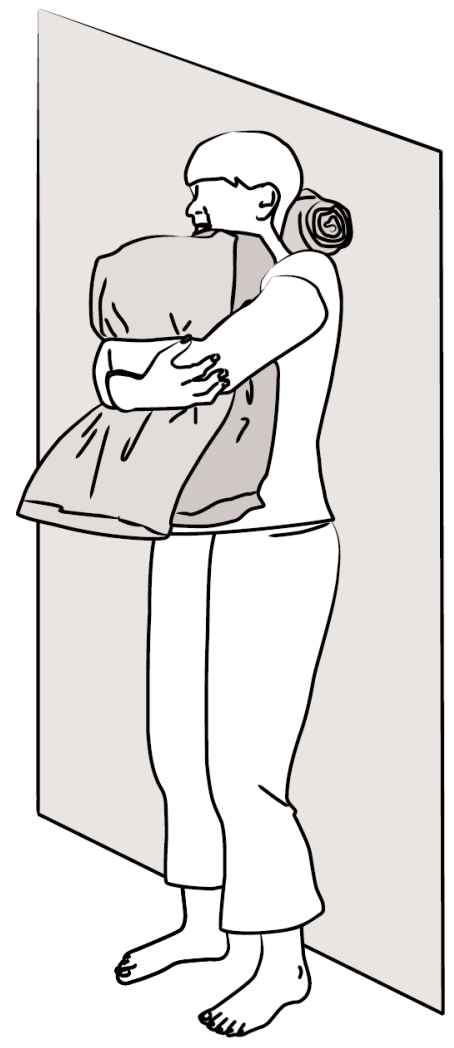




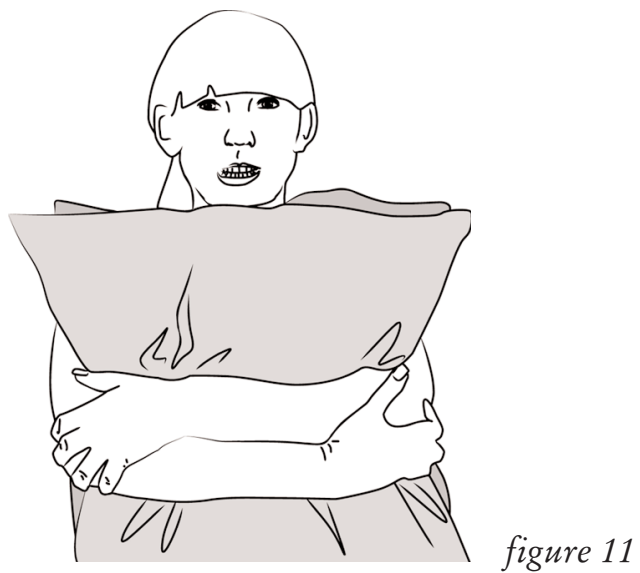

6. Imagine the pillows are your Natural Child — lively and innocent, but young and vulnerable. Or your pillows can be your »puppies«. Now imagine there is someone across the room who wants to hurt your Natural Child / puppies.

7. Bring your lower jaw forward, let your eyes glare with strong intent, and feel your determination to protect your Natural Child / puppies. You may find it easier to protect your "puppies « than your Natural Child. You can also shift between the two possibilities.

8. Say out loud something like, »I can protect you! « (talking to your Child / puppies) or »I will protect this Child / these puppies! (talking to the imaginary abuser).

9. Say »I can« or »I will« out loud again, but this time stretch out the »an-an-an« or »il-il-il« sound for about 5 seconds. The »an-an-an« or »1-il-il« sound should slowly rise to higher pitch as you gradually keep hugging yourself tighter and pulling the pillows into your chest.

10. Now take a very short breath, and stretch out the sound »an-an-an« or $» \mathrm{il}-\mathrm{il}-\mathrm{i} 1 \ll$ again.

$>$ Do this for several breaths, pausing only to catch quick small breaths. This is similar to the driver of a sports car shifting gears (taking a breath) as the motor revs up.

$>$ Keep increasing the tension in your arms and hands as you make the »an-an-an « or »il-il-il« sound and don't forget to let the voicepitch rise along with the tightening of the arms.

11. Occasionally, check into your body and savor the feeling of power as it slowly builds. 
12. If you start coughing, stop briefly - it's a sign your system has not relaxed and opened up enough to integrate the increased energetic charge.

13. Your voice will naturally rise toward a high-pitched scream as your muscular tension increases; however, you should stop short of screaming.

14. Occasionally check to see that you are well-grounded in your feet, with your legs vibrating, and that:

$>$ You keep contact between the pillow and your chest, and your back against the wall;

$>$ Your lower jaw stays forward, and your eyes stay determined.

15. After you have run out of sound or your arms are too tired, let go of the pillows with your hands, but let your legs continue to vibrate as you discharge energy into the ground.

16. Now bend over and integrate your emotional and energetic flow(s). If you put your pillows on the floor between your legs you can still keep an eye on them while taking a break from protecting them.

17. Repeat Steps 7 to 16 at least twice more.

18. Close your eyes and sense any changes in your body, your emotions and your overall sense of yourself:

$>$ Especially note if you are feeling considerably warmer - indicating that your core energy has reached your periphery and your boundary has been strengthened energetically

$>$ Open your eyes and note any changes in your vision: are your eyes more open? Is your eyesight any different? Are colors deeper? Do you feel more »into « your eyes?

$>$ Do people's faces look different, and do you have different feelings towards them than before?

$>$ Do you feel more "present «? More in your Adult, rather than your False Self / Adaptive Self? 
»Charging/Containing « Errors — Watch Out!

$>$ Are your elbows and/or knees straightening? Your lower jaw losing its forward thrust? Eyes closing, growing dull or »spacing out«? Are your legs losing their vibrations? Do your hands intermittently let go of your elbows? or fail to grasp the elbows increasingly strongly?

$>$ Are you losing your determination to protect your »puppies «?

$>$ Do you state the full goal in words instead of just staying with the draren-out last sound (as in »I can-an-an-an « or »I will-il-il-il«)?

$>$ Do you fail to keep an ascending voice pattern by allowing:

$>$ the voice to jump up in steps? (Plateau'ing)

$>$ the pitch to drop off before each breath? (Collapsing)

$>\quad$ all the breath and sound to expel suddenly? (Blowing out)

$>$ Accompanying the above sabotaging could be feelings of collapse, like »I can't « or » What's the use? « or »Why try? « or »Nothing does any good $\ll$.

\section{Exercise 3: Your Adult Surrendering to Your Natural Child}

Exercise 3 involves our Adult temporarily surrendering our character defenses in order to let the heartfelt expansive feelings of the Natural Child emerge. If our boundaries are "too tight", Surrendering is the most important component for us and needs to be experienced daily at home and/or work.

This exercise also requires support initially from a Bioenergetic colleague.

In this exercise, the Boundary Supports (cushions and pillows) will encourage your Natural Child's energetic aliveness (instincts, impulses and feelings) to emerge, and your Adult will give the Child permission to express this aliveness. Together, the increase in aliveness and conscious permission will allow the child more possibility to "just $\mathrm{Be} \ll$.

Equipment: two sofa cushions or a very large thick pillow, about 8 inches (20 $\mathrm{cm}$ ) thick, lightly squeezed between the legs; three bed pillows; a wall or door.

It's helpful if you've experienced Exercise 1 at some time previous to undertaking this. It is also very helpful if you complete Exercise 2 immediately before beginning this exercise, as Charging/Containing will make it easier for you to surrender to your Natural Child.

Before beginning the exercise, read all instructions and position the equipment as in Figure 12.

Our Natural Child just wants to »BE« - be fully alive, be expansive, be 
free to express itself, be sexual, be open, be creative, be tender or aggressive, be searching for pleasure, etc.

However, protective aspects in our personality are frightened that all this »Being " will cause the Natural Child again to be injured again, as »just being " caused us to be injured in childhood. These protective aspects guard against a recurrence of primal injury through muscular and energetic contractions. Our protective aspects guard against free expression through conscious inhibitions, e.g., "should not « and "ought not «.

With all this guarding, our Natural Child feels imprisoned and is not free to $»$ just Be .

Our Adult needs to return to the Child, take charge of the situation and begin to reduce some of the guarding (most of which is now unnecessary) and give our Natural Child more permission to "just Be«.

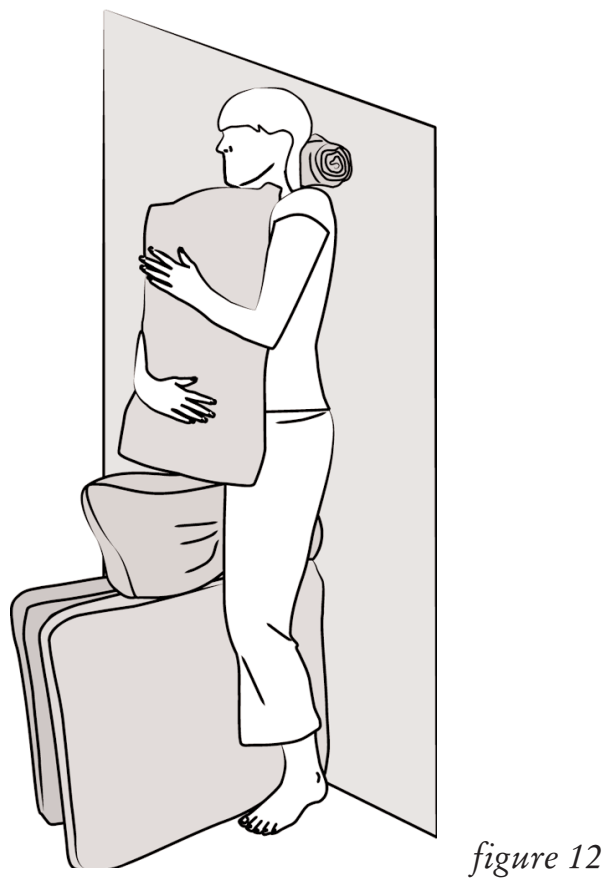

1. Arrange your equipment as in Figure 12:

> Stand with your back against a wall or door, your feet firmly on the floor and your heels close to the wall; do not lean against the wall 
$>$ Straddle the two sofa cushions that have been placed vertically, flat side to flat side

$>$ Use a pillow to fill the space between the tops of the cushions and the juncture of inside of legs with pelvis

$>$ With your knees barely bent, alternate bending and straightening them very slightly - just enough to keep a little life in the legs.

2. Place one pillow on your upper chest (and if you wish tuck it under your chin) and the other one covering your stomach and lower belly, keeping a hand on each pillow. If more convenient, you might use a king-size pillow (as in Figure 12).

3. The insides of your arms, legs, chest and belly should now feel contained and supported.

4. Throughout the exercise your Bioenergetic colleague (»therapist «) will be making sure your equipment is positioned correctly in order for you to feel fully contained and supported.

5. Very lightly squeeze the cushions between your legs and hold the pillows firmly to your chest.

6. Close your eyes, let your jaw relax, breathe normally and let a little sound emerge naturally.

7. Now say out loud to your Natural Child something like, »I won't let anyone hurt you again. You are safe with me«. (This continues the theme from Exercise 2.)

8. Say again, "You are safe « and pause to note if there is an increase in the vibration of your body. Say out loud something like, »Go ahead, live freely, just $B E$ «. Again, pause and note the reaction of your Natural Child.

9. Integrate any increase in excitation / vibration by continuing to bend and straighten your knees slightly, which will help the vibratory movement flow more freely throughout your body.

10. For the next 5 to 15 minutes, continue this process of talking to your Natural Child in very brief sentences, and pause to note any increase in excitation / vibratory movement. Keep bending and straightening the knees to integrate the increased flow.

11. If your tendency is to stand fully on your feet, occasionally lean slightly against the wall and note any difference in excitation / vibratory movement. Conversely, if you tend to want to lean against the wall, occasionally stand fully on your feet and note the difference.

12. If the increase in excitation / vibratory movement feels insufficient, bend and straighten your legs more deeply while pressing your feet more strongly on the floor. 
13. If you wish, your »therapist « may place a rolled-up towel between the back of your neck and the wall and/or between your lower back and the wall and perhaps even a blanket between your back and the wall. Your therapist may sense you need to have her hand on your forehead for additional support.

14. You will know when you are finished; bend over so that your fingertips touch the floor lightly, and continue to bend and straighten your legs.

15. Come up, open your eyes and note any changes in your vision. Are your eyes more open? During the exercise:

$>$ Did you feel safe, contained, supported, secure, comfortable?

$>$ Did you notice any increase in body warmth? If so, where? Any flow of pleasure?

$>$ Did you feel a slight anxiety that accompanied the flow of warmth? (Anxiety could occur because, as your core energy begins to expand, due to the safety of containment, your unconscious characterological contraction will block it. The opposition of these forces creates anxiety.)

\section{Utilizing Boundary Supports}

\section{Equipment}

Principal Boundary Supports, as used in Exercise 3, include two cushions and two or three pillows. Secondary Boundary Supports include »sock pads " (a folded-over thick sock that fits comfortably under the arch of the foot); rolled-up towels for back of neck and lower back when standing against a wall; and a blanket.

\section{Principal Effects}

The effects of Boundary Supports can be quite varied, depending on the exercise position chosen, the supports that are used, and whichever exercise has immediately preceded. Generally, when Boundary Supports are used:

1. The energetic charge can come up very quickly and strongly; e. g., if you have a holding in your lower back, it may begin to ache, since the increased charge cannot move easily through the holding.

2. Many people experience spontaneously their Natural Child, manifesting pleasurable body warmth, an expansive open-heartedness and joy. 
3. Some people, on the other hand, regress spontaneously to their Primally Wounded Child, re-experiencing some of their early developmental emotional trauma and energetic contractions.

The above three possible reactions come as a surprise to most people, as neither they nor their therapist has made any verbalizations, nor any specific attempt to further charge the body, nor to elicit any emotional or energetic response.

Therapeutically, these powerful emotional / muscular / energetic responses can be organized and focused through simple verbalizations made out loud by our Adult (as in the exercises in this paper).

The therapist's suggestions for appropriate verbalizations depends on his/her assessment of our boundary condition:

> If our therapist assesses our boundary as »too loose«, he/she will suggest verbalizations for our Adult that will help give us feelings of containment, assurance, security and safety - allowing us to risk more energetic charge.

> If our therapist assesses our boundary as »too tight«, he/she will suggest verbalizations for our Adult that will help give us feelings of relaxation and melting of the rigid characterological defenses that arose from rejection in our childhood.

\section{Explaining the Effects}

As infants one of our principal needs is to have chest-to-chest contact with our mother's body and, to a lesser degree, have our back contacted (where our mother supports us while lifting us, nursing us, etc.).

At a slightly older age, being able to hold onto our mother and later our father with the insides of our arms and the insides of our legs means that we possess them; they cannot leave without our permission, and survival is assured.

Our wanting to hug others and bring them to our chest as adults is a continuation of our very early need for Boundary Support; e. g., for some of us a deeper sleep occurs when we are in contact with a loved one's body.

It appears that most of us and our clients did not receive enough of this highly important chest / belly / back / inside arms / inside legs contact (not to mention sucking) when we needed it in our development.

Because of this sensorial deprivation, life-impulses that naturally would have aggressively moved out into the world with both heartfelt and assertive 
feelings instead contracted inward. Consequently, we live with a chronic contraction of our life-impulses. Studies of infants who are not touched enough in hospitals, and also the very concrete data on monkeys who lose their mothers, support the above statements. In short, if the mothering environment is hostile or cold or absent, the life-impulse contraction can be severe.

Accordingly, when our chest, belly, inside arm and inside leg surfaces and our foot arches are contacted comfortably, there will be a deep unconscious energetic charge that moves swiftly and intensely toward the periphery of our body. This accounts for the warmth with which the energetic charge presents itself.

This outward flow to our periphery is countered by our characterological muscular and energetic contractions. The conflict between the outward flow and the inward contraction can create anxiety, depending on the exercise positions. Any anxiety needs to be grounded, and time reserved at the end of the session for muscular, energetic and emotional integration.

\section{Adaptations for Ongoing Therapy}

Boundary Supports can be adapted for a great many traditional Bioenergetic exercises. Moreover, using them frees up the therapist's hands for other supportive functions; e.g., holding the head, placing a hand on the forehead (third eye), or on the upper back, holding the client's hand, etc.

Bioenergetic therapists who have experienced Boundary Supports in workshops have become enthusiastic about their benefits for their own clients. These therapists have adapted the supports to fit their style of personal therapy; e.g., Garry Cockburn and Pye Bowden of the New Zealand Society developed toe arch pads. Other Bioenergetic therapists have given me valuable feedback on the experience of their clients, and I will acknowledge more fully the contributions of these others later.

Boundary Supports seem to give our organism the comfort, assurance, security and safety to begin to take the risk to expand energetically again. It is probable we need to use these supports many times, over an extended period, before our core energetic impulses, instincts and feelings can flow more naturally and easily to the periphery of our body and help us in our boundary-building. Hence the need to adapt and include the supports in a self-help program. 


\section{Future Investigations}

Two areas touched on in this paper hold promise for further investigation:

$>$ Establishing direct communication between Adult / Ego and Natural Child / Body. Preliminary investigations have established that certain body parts - e.g., pelvis, legs and eyes - can directly respond with increased excitation and involuntary movement when talked to aloud by the Adult / Ego. This in turn strengthens the Adult by strengthening its connection to the Body.

$>$ Boundary Supports, which lead to increased energetic expansiveness, energetic charge and involuntary movement. These, when coupled with increased communication between Adult and Child, can strengthen the Adult and the Child, as well as the connection between them.

These investigations are but the tip of the iceberg in explorations to heal the split between the Ego and the Body.

\section{References}

Lowen, A. (1967). Betrayal of the Body. New York, MacMillan Publishing Co.

Lowen, A. (1983). Narcissism. New York, MacMillan Publishing Co.

\section{About the Author}

Bennett Shapiro, Ph.D. is a member of the IIBA Faculty and teaches in the U.S., Canada and Europe. He has a private practice in Victoria, B.C., Canada, and is currently writing two workbooks on various aspects of Boundary-Building.

Bennett Shapiro, Ph.D., 1542 Prospect Place, Victoria, B.C., V8R 5X8 Canada benandmillie@shaw.ca 